\title{
A review of EBV-positive mucocutaneous ulcers focusing on clinical and pathological aspects
}

\author{
Tomoka Ikeda, ${ }^{1)}$ Yuka Gion, ${ }^{2)}$ Tadashi Yoshino, ${ }^{1)}$ Yasuharu Sato, ${ }^{1,2)}$
}

\begin{abstract}
Epstein-Barr virus (EBV)-positive mucocutaneous ulcers (EBVMCUs) were first described as a lymphoproliferative disorder in 2010. Clinically, EBVMCUs are shallow, sharply circumscribed, unifocal mucosal or cutaneous ulcers that occur in immunosuppressed patients, including those with advanced age-associated immunosenescence, iatrogenic immunosuppression, primary immune disorders, and HIV/AIDS-associated immune deficiencies. In general, patients exhibit indolent disease progression and spontaneous regression. Histologically, EBVMCUs are characterized by the proliferation of EBV-positive, variable-sized, atypical B-cells. According to conventional histopathologic criteria, EBVMCUs may diagnosed as lymphomas. However, EBVMCUs are recognized as pseudomalignant lesions because they spontaneously regress without anti-cancer treatment. Therefore, overtreatment must be carefully avoided and multilateral differentiation is important. In this article, we reviewed previously reported EBVMCUs focusing on their clinical and pathological aspects in comparison with other EBV-positive B-cell neoplasms.
\end{abstract}

Keywords: EBV-positive mucocutaneous ulcer, clinical features, pathological features, immunosuppression

\section{INTRODUCTION}

Epstein-Barr virus (EBV)-positive mucocutaneous ulcers (EBVMCUs) were first described as a distinct clinicopathological entity in 2010 when Dojcinov et al. reported 26 patients with ulcerative lesions confined to the oropharynx, skin, and gastrointestinal tract. ${ }^{1}$ The lesions were characterized by the proliferation of EBV-positive, variably sized, atypical B-cells that may resemble Hodgkin and ReedSternberg (HRS)-like cells. As the patients were immunosuppressed, demonstrating either age-related immunosenescence or iatrogenic immunosuppression, EBVMCUs were later described as a new disease type by the World Health Organization. $^{2}$

EBVMCUs are shallow, sharply circumscribed, mucosal or cutaneous ulcers with underlying polymorphous infiltration. The HRS-like cells that are observed in the lesions, as well as any observed immunoblasts, demonstrate B-cell immunophenotypes, i.e., CD20 expression; therefore, the ulcers were originally classified as EBV-positive diffuse large B-cell lymphomas (EBV-positive DLBCLs), but were later recognized as a unique disease type, pathologically distinct from lymphomas. However, some characteristics of
EBVMCUs overlap with those of immunodeficiency-associated lymphoproliferative disorders (LPDs).

In general, patients with EBVMCUs exhibit indolent disease progression and spontaneous regression. Although radiotherapy or chemotherapy may be considered as therapeutic options, most patients have spontaneous regression when their immunosuppression is reduced or discontinued; only one disease-associated death has been reported. ${ }^{3}$ In this article, we describe the clinicopathological aspects of EBVMCUs.

\section{EBV BIOLOGY}

EBV, also known as human herpes virus 4, is a member of the herpes virus family and is one of the most common human viruses. ${ }^{4-8}$ Approximately $95 \%$ of people become infected with this virus during childhood because it may be directly transferred between individuals through saliva. Although infections sometimes manifest as infectious mononucleosis, many are asymptomatic.

EBV preferentially infects B lymphocytes through the interaction of the major viral surface glycoprotein (gp350) with a B lymphocyte receptor (CD21); a second viral

\footnotetext{
Received: December 21, 2018. Revised: March 19, 2019. Accepted: March 26, 2019. Onlune Published: June 28,2019

DOI:10.3960/jslrt.18039

${ }^{1}$ Department of Pathology, Okayama University Graduate School of Medicine, Dentistry and Pharmaceutical Sciences, Okayama, Japan, ${ }^{2}$ Division of Pathophysiology, Okayama University Graduate School of Health Sciences, Okayama, Japan.

Corresponding author: Dr. Yasuharu Sato, Division of Pathophysiology, Okayama University Graduate School of Health Sciences, 2-5-1 Shikata-cho, Kita-ku, Okayama 700-8558,

Japan. E-mail: satou-y@okayama-u.ac.jp

Copyright (C) 2019 The Japanese Society for Lymphoreticular Tissue Research

(cc) BY-NC-SA This work is licensed under a Creative Commons Attribution-NonCommercial-ShareAlike 4.0 International License.
} 
Table 2. Case reports and series. (2010-2018)

\begin{tabular}{|c|c|c|c|c|}
\hline & Cases & $\begin{array}{l}\text { Mean age } \\
\text { (years) }\end{array}$ & $\begin{array}{l}\text { Age range } \\
\text { (years) }\end{array}$ & $\begin{array}{c}\text { Sex } \\
\text { (male/female) }\end{array}$ \\
\hline \multicolumn{5}{|c|}{ Other Iatrogenic Immunodeficiency-Associated EBVMCU } \\
\hline Oropharyngeal & 46 & 65.2 & $17-84$ & $17 / 29$ \\
\hline Skin & 14 & 66.2 & $49-81$ & 3/11 \\
\hline Gastrointestinal & 20 & 59.9 & $26-81$ & $11 / 9$ \\
\hline \multicolumn{5}{|c|}{ EBVMCU due to age-associated immunosenescence } \\
\hline Oropharyngeal & 23 & 76.7 & $51-101$ & $10 / 13$ \\
\hline Skin & 7 & 81.3 & $74-89$ & $5 / 2$ \\
\hline Gastrointestinal & 3 & 69.3 & $64-79$ & $1 / 2$ \\
\hline \multicolumn{5}{|c|}{ HIV/AIDS-Associated EBVMCU } \\
\hline Palate & \multicolumn{4}{|c|}{2 cases (54-year-old male, 36-year-old female) $)^{20}$} \\
\hline \multicolumn{5}{|c|}{ Primary Immunodeficiency-Associated EBVMCU } \\
\hline Gingiva & \multicolumn{4}{|c|}{45 -year-old female with T-cell deficiency ${ }^{14}$} \\
\hline Esophagus & \multicolumn{4}{|c|}{ 61-year-old male with hypogammaglobunemia ${ }^{15}$} \\
\hline Nasopharyngeal & \multicolumn{4}{|c|}{ 16-year-old male with CHARGE syndrome ${ }^{3}$} \\
\hline \multicolumn{5}{|c|}{ Chronic Antigenic Stimulation-Associated EBVMCU } \\
\hline Sinus & 59 -year-old female ${ }^{46}$ & & & \\
\hline \multicolumn{5}{|c|}{ EBVMCU of Unclear Etiology } \\
\hline Oropharyngeal & \multicolumn{4}{|c|}{2 cases (49-year-old female, 49 -year-old female) $)^{3,6}$} \\
\hline Total & 121 & 66.4 & $16-101$ & $50 / 71$ \\
\hline
\end{tabular}

EBVMCU cases in 2010 to $2018 .^{1,3,6,14-48}$

or cutaneous ulcers, ${ }^{49}$ with $>70 \%$ of the ulcers occurring in the oral mucosa (Figure 1). As EBVs are secreted into saliva and local trauma or inflammation is likely to occur in the oral cavity, there is a possibility of EBVMCUs developing intraorally. ${ }^{50}$ Some cases result in eating disorders without any systemic symptoms, including lymph node swelling or B symptoms, i.e., fever, night sweats, and weight loss.

EBVMCUs emerge when the host-virus homeostasis is not maintained, i.e., when the virus overwhelms the host's immune response. Specifically, ulcer eruption may result from immune abnormalities caused by inflammation and immunosuppression. Dojcinov et al. first reported the ulcers in patients characterized by advanced age who were undergoing iatrogenic immunosuppression using MTX, azathioprine, cyclophosphamide, or tumor necrosis factor- $\alpha$ inhibitor. ${ }^{1}$ Patients with EBVMCUs who were not using immunosuppressants were elderly ( $>60$ years old), leading to the suggestion that EBVMCUs also develop as a result of age-associated immunodeficiency that is mainly caused by $\mathrm{T}$ cell hypofunction. ${ }^{1}$ After their report, EBVMCUs were also reported in patients with primary immunodeficiencies, ${ }^{14,15}$ solid organ or bone marrow transplant recipients, ${ }^{16-19}$ and in those with HIV/ acquired immune deficiency syndrome (AIDS).$^{20}$ One case of ulceration was reported in an immunosuppressed patient with inflammatory bowel disease; therefore, the possibility of EBVMCUs being involved in such cases needs to be considered. ${ }^{21}$ Among the previously reported cases, $80(66.1 \%)$ were iatrogenic immunodeficiency-associated EBVMCUs and 33 (27.3\%) were associated

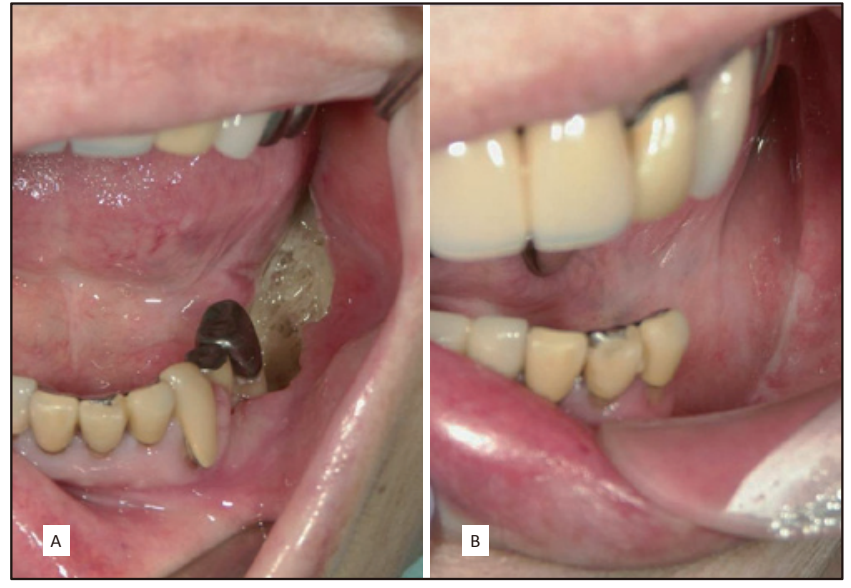

Fig. 1.

Macroscopic findings of a gingival Epstein-Barr virus-positive mucocutaneous ulcer.

The ulcer appearance while the patient was undergoing methotrexate treatment $(\boldsymbol{A})$. After reducing the methotrexate dose, the lesion spontaneously resolved $(\boldsymbol{B})$.

with age-associated immunosenescence. EBVMCUs have also been reported in patients with primary immunodeficiencies ( 3 cases) and in those with HIV/AIDS ( 2 cases). During follow-up (1-180 months), spontaneous regression was observed in 6 cases and complete remission was observed in 79 cases following the reduction of immunosuppression, chemotherapy, or radiotherapy; 7 cases relapsed, ${ }^{1,3,38}$ but only 3 developed progressive disease. . $^{3,1522}$

Before EBVMCUs were defined, there were several 
reports of oral ulcerations occurring as a side effect of MTX therapy. ${ }^{51}$ In such cases, the ulcers regressed following reductions in the immunosuppression regimes. Thus, these ulcers were not considered to be EBV-related, but rather the result of treatment-associated toxicity. These ulcers were also regarded as being nonspecific based on microscopic observations; however, most of the case reports only described the associated clinical features without histological evaluation.

\section{CLINICAL MANAGEMENT AND PROGNOSIS}

Almost all EBVMCU cases have some degree of spontaneous regression following cessation or reduction of the immunosuppressive treatment for autoimmune disorders such as rheumatoid arthritis. Some patients with these lesions have been treated by radiotherapy and rituximab or other forms of chemotherapy, and often demonstrate complete remission. However, whether the lesions responded to the treatment or spontaneously resolved remains unknown.

The ulcers rarely spread to distant sites, but they have been observed to spread locally and relapse after regression. Hodgkin lymphoma (HL)-like EBVMCUs sometimes do not regress. ${ }^{52}$ Therefore, the patients in such cases are treated by radio- or chemotherapy; these patients also often exhibit remission. As progressive disease and the subsequent development of HL was observed in a rare case, the ulcers may also be associated with HL. ${ }^{22}$ Other than this one case, there has been only one disease-associated death among the reported cases and series. ${ }^{3}$ Thus, other EBV-positive LPDs have a poorer prognosis than EBVMCUs.

\section{PATHOLOGICAL FEATURES}

The localized mucosal or cutaneous ulcers are characterized by the presence of EBV-positive atypical immunoblasts or HRS-like cells (Figure 5). The atypical cells range in size from small to large, and accompany dense polymorphic infiltration with the variable presence of other inflammatory cells such as plasma cells (polymorphous type) (Figure 2, 4). Some cases have demonstrated histological findings similar to those associated with DLBCL or cHL (Figure 3, 5). Occasionally atypical lymphoid cells demonstrated plasmacytoid features (Figure 6). In these cases, the cells exhibit characteristics of activated B lymphocytes, including (in most cases) CD20 and CD30 expression. These cells are often also positive for CD79a, PAX5, and OCT2, with variable expression of BOB1. CD15 is expressed in approximately half of the cases and MUM1 is typically expressed. ${ }^{2}$ These immunohistochemical results strongly support the origination of these atypical cells from B cells. Although these histological findings are similar to those associated with cHL, many of the B lymphocytes being CD20-positive is different from cHL. In addition, extranodal lesions are rare in patients with cHL. Thus, cHL and EBVMCU can be distinguished based on their respective clinicopathological features. HRS-like cells are seen in EBV-positive LPDs, but

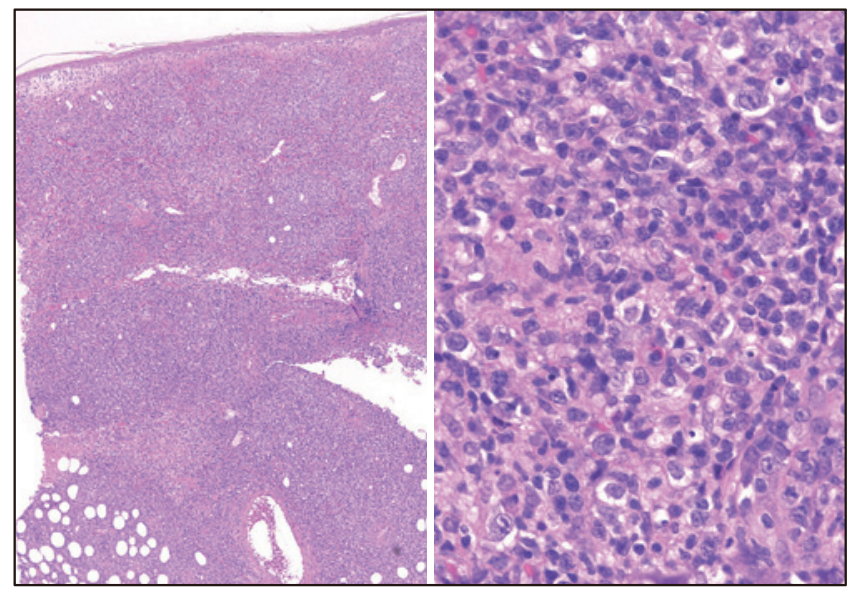

Fig. 2.

A cutaneous Epstein-Barr virus-positive mucocutaneous ulcer (polymorphous type) on the lower leg of a 72-year-old female undergoing methotrexate treatment.

Atypical lymphoid cells with a polymorphous morphology are infiltrating the epidermal, dermal, and subcutaneous tissues.

After reducing the methotrexate dose, the lesion spontaneously resolved.

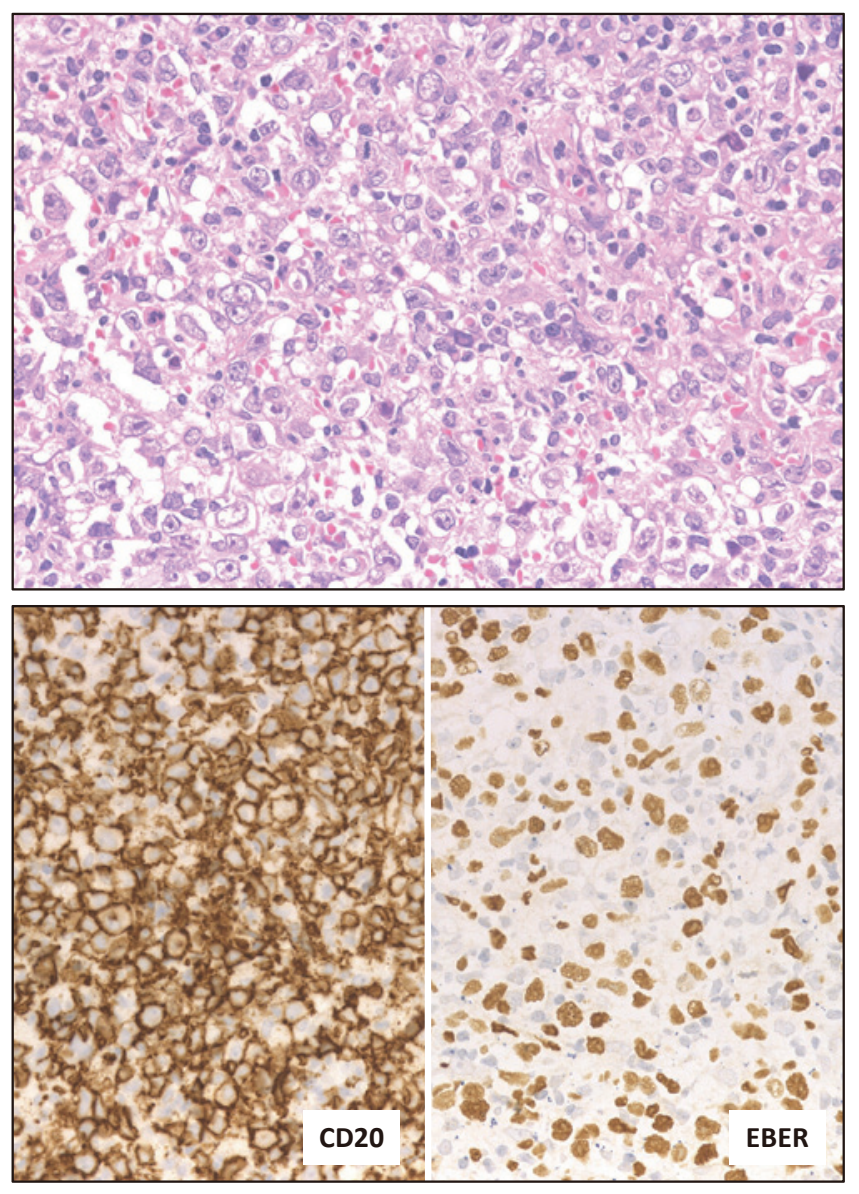

Fig. 3.

An Epstein-Barr virus-positive mucocutaneous ulcer (diffuse large B-cell lymphoma [DLBCL] type) in the nasopharyngeal mucosa of an 80-year-old female undergoing methotrexate treatment.

This case resembles DLBCL morphology.

The lymphoid cells are positive for CD20 and Epstein-Barr virusencoded small RNA.

Following chemotherapy that included rituximab, the lesion showed complete remission. 


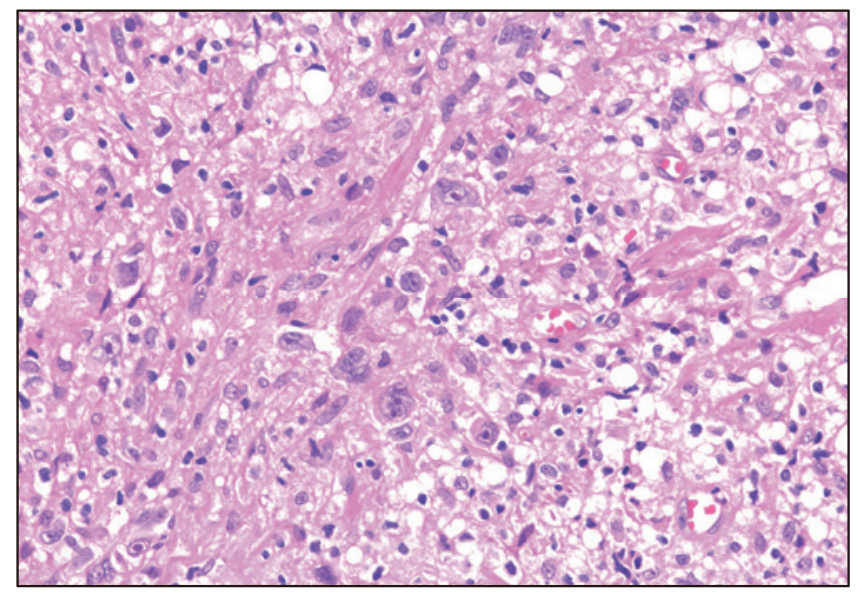

Fig. 4.

A gingival Epstein-Barr virus-positive mucocutaneous ulcer (polymorphous type) in a 91-year-old male undergoing methotrexate treatment.

The lesion showed polymorphous morphology with Hodgkin and Reed-Sternberg-like cells.
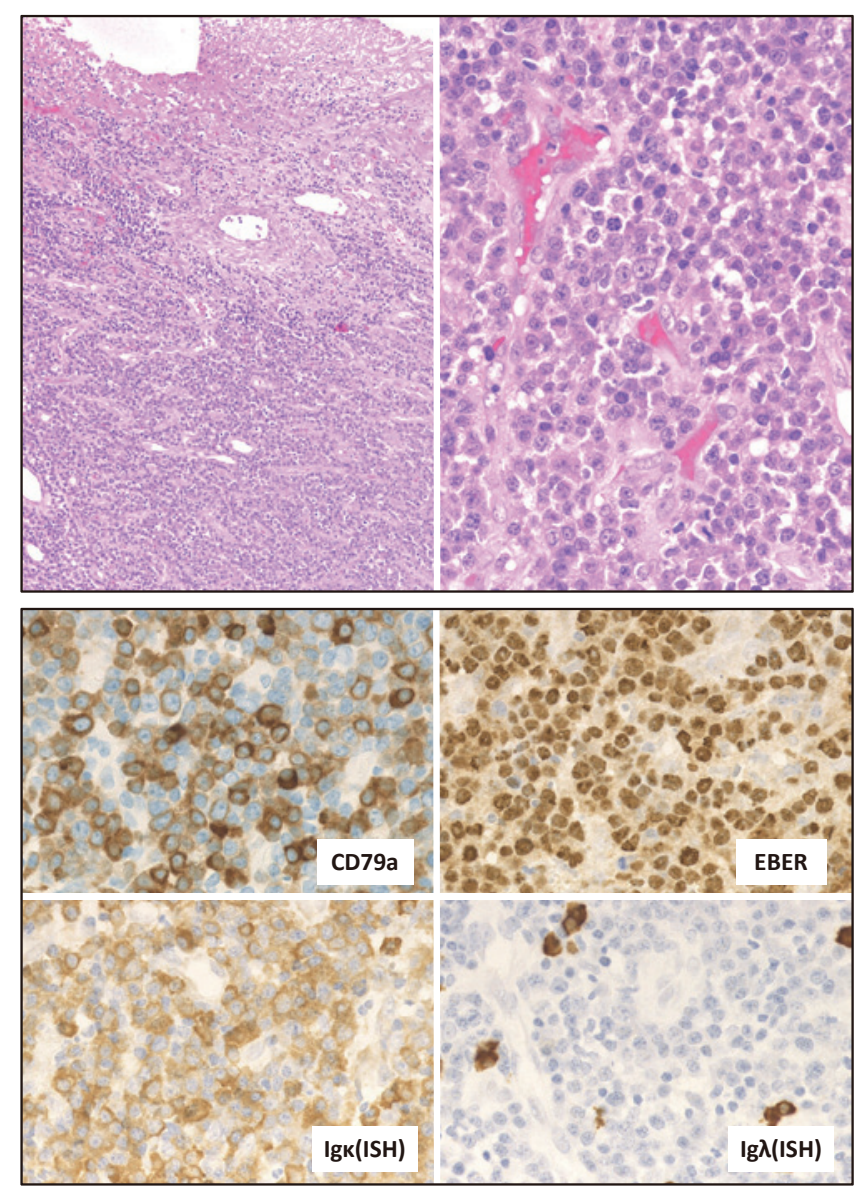

Fig. 5.

A gingival Epstein-Barr virus-positive mucocutaneous ulcer (diffuse large B-cell lymphoma [DLBCL] type) in a 69-year-old male. Large, atypical lymphoid cells, with plasmacytoid differentiation are infiltrating the subepithelial lesion.

This lesion is similar to a DLBCL with plasma cell differentiation. These atypical lymphoid cells are CD20-negative and positive for CD79a and Epstein-Barr virus-encoded small RNA.

Immunoglobulin light chain analysis, using in situ hybridization, showed a $\kappa$ chain monotype.

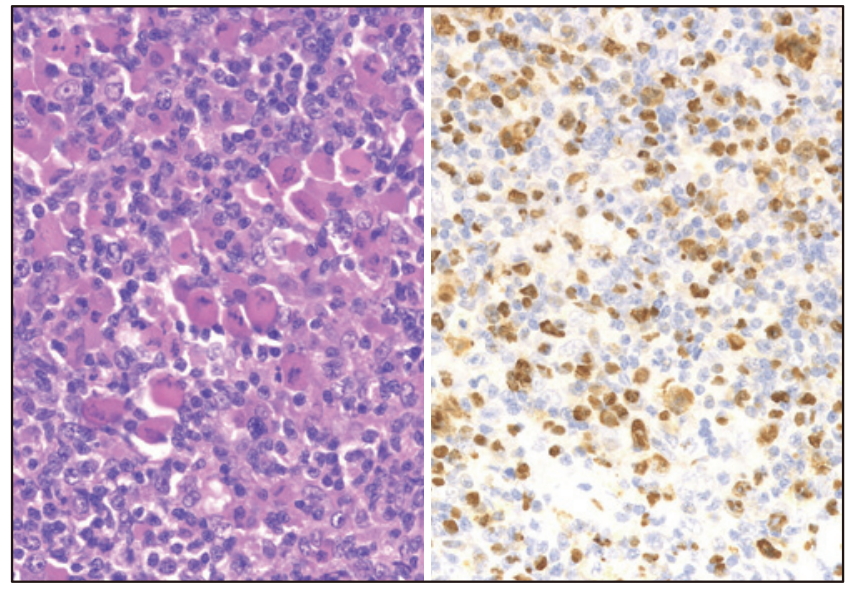

Fig. 6.

A lingual Epstein-Barr virus-positive mucocutaneous ulcer (mucosa-associated lymphoid tissue lymphoma type) in a 66-yearold female undergoing methotrexate treatment.

Atypical, medium-sized lymphoid cells demonstrate plasmacytoid features and Russel bodies.

In situ hybridization shows that the atypical cells are Epstein-Barr virus-encoded small RNA-positive.

After reducing the methotrexate dose, the lesion spontaneously regressed.

the B lymphocytes in patients with infectious mononucleosis or PTLD are CD30-positive and CD15-negative; CD15 expression is also downregulated in cases of EBV-positive, MTX-associated LPD.

Mucosal and cutaneous EBVMCU lesions exhibit dense polymorphic infiltration with the variable presence of inflammatory cells, including plasma cells, histiocytes, lymphocytes, and eosinophils. Apoptotic bodies and necrosis are also often noted. These infiltrating lymphocytes are mainly CD8-positive T cells and $31 \%$ of them demonstrate $T$ cell receptor $(T C R)$ gene rearrangements. ${ }^{1}$

EBV-positive DLBCL is a disease that requires distinction from EBVMCUs based on its histology and prognosis. EBV-positive DLBCLs were initially reported to be associated with aging. This disease is characterized by poor outcomes, and is a high-grade lymphoma that presents with CD20-positive, CD30-positive, and sometimes CD15positive HRS-like cells. Polymerase chain reaction characterization revealed more clonal immunoglobulin heavy chain $(\mathrm{IgH})$ gene rearrangements associated with EBV-positive DLBCL than with EBVMCUs. ${ }^{1,13}$ However, differentiating between EBVMCUs and EBV-positive DLBCLs is difficult. Aside from EBVMCUs typically being "localized lesions", consideration of the clinical findings is necessary when distinguishing between the two.

\section{GENETIC FEATURES}

There are several reports on the search for clonality in age-related and immunodeficiency-related EBVMCUs. ${ }^{1,23}$ Dojcinov et al. reported that $38 \%$ of their cases exhibited $\operatorname{IgH}$ gene rearrangements and $31 \%$ exhibited TCR gene rearrangements when evaluated using polymerase chain reaction. 
Age-related EBVMCUs have been found to have lower clonality than EBV-positive DLBCLs, ${ }^{13}$ suggesting that EBVMCUs are not true tumors.

As EBV-positive cells are B lymphocytes, the $I g H$ gene rearrangements of EBVMCUs are associated with B cells. Furthermore, EBVMCUs may present $T C R$ gene rearrangements even though EBV-positive cells are B cells. A previous report suggested that $T C R$ gene rearrangements are associated with a limited $\mathrm{T}$ cell repertoire associated with EBV infections in patients who are aged and immunosuppressed. ${ }^{1}$ The $\mathrm{T}$ cells responsible for immune responses are the mature memory $\mathrm{T}$ cells that are CD8-positive. It is possible that $\mathrm{T}$ cells cannot recognize the EBV epitope because T cell epitope recognition is restricted in older patients and in those with other immunodeficiencies. ${ }^{53}$ This may enable an increase in the number of EBV-positive cells. As a result, the human body may allow the proliferation of mature memory $\mathrm{T}$ cells to elicit an immune response and be involved in clonality.

Ohata et al. investigated several gene mutations (MYD88, CD79A, CD79B, CARD11, and EZH2), and although none were associated with EBVMCUs, more than $30 \%$ of tumor tissues from EBV-negative DLBCLs contained mutations. ${ }^{24}$

\section{CONCLUSION}

EBVMCUs are a newly described entity in the World Health Organization classification. ${ }^{2}$ They are ulcerative lesions localized to the skin and mucosa that are characterized by the presence EBV-positive variably sized B-cells. To appropriately treat EBVMCUs, clinicians need to be able to distinguish them from DLBCLs and cHL based on their clinicopathological findings. Although there is currently no established treatment regimen due to the lack of evidence, future case studies are expected to rectify this.

\section{CONFLICT OF INTEREST}

The authors report no potential conflicts of interest.

\section{REFERENCES}

1 Dojcinov SD, Venkataraman G, Raffeld M, Pittaluga S, Jaffe ES. EBV positive mucocutaneous ulcer-a study of 26 cases associated with various sources of immunosuppression. Am J Surg Pathol. 2010; 34 : 405-417.

2 Gaulard P, Swerdlow SH, Harris NL, Sundstrom C, Jaffe ES. EBV-positive mucocutaneous ulcer. In: Swerdlow SH, Campo E, Harris NL, et al. (eds): WHO Classification of Tumours of Haematopoietic and Lymphoid Tissues, Revised 4th ed, Lyon, International Agency for Research on Cancer. 2016; pp. 307-308.

3 Natkunam Y, Goodlad JR, Chadburn A, et al. EBV-Positive B-cell proliferations of varied malignant potential. Am J Clin Pathol. 2017; 147 : 129-152.

4 Komano J, Sugiura M, Takada K. Epstein-Barr virus contributes to the malignant phenotype and to apoptosis resistance in Burkitt's lymphoma cell line Akata. J Virol. 1998; 72 : 9150-9156.

5 Komano J, Maruo S, Kurozumi K, Oda T, Takada K. Oncogenic role of Epstein-Barr virus-encoded RNAs in Burkitt's lymphoma cell line Akata. J Virol. 1999; 73 : 9827-9831.

6 Roberts TK, Chen X, Liao JJ. Diagnostic and therapeutic challenges of EBV-positive mucocutaneous ulcer: a case report and systematic review of the literature. Exp Hematol Oncol. 2016; 5 $: 13$.

7 Kutok JL, Wang F. Spectrum of Epstein-Barr virus-associated diseases. Annu Rev Pathol. 2006; 1 : 375-404.

8 Liebowitz D. Epstein-Barr virus and a cellular signaling pathway in lymphomas from immunosuppressed patients. N Engl J Med. 1998; 338 : 1413-1421.

9 Price AM, Luftig MA. To be or not IIb: a multi-step process for Epstein-Barr virus latency establishment and consequences for B cell tumorigenesis. PLoS Pathog. 2015; 11 : e1004656.

10 Kojima M, Morita Y, Nakamura N, et al. Plasmacytic hyperplasia in age-related Epstein-Barr virus-associated lymphoproliferative disorders: a report of two cases. Pathol Res Pract. 2008; $204: 267-272$.

11 Oyama T, Yamamoto K, Asano N, et al. Age-related EBVassociated B-cell lymphoproliferative disorders constitute a distinct clinicopathologic group: a study of 96 patients. Clin Cancer Res. 2007; 13 : 5124-5132.

12 Shimoyama Y, Yamamoto K, Asano N, et al. Age-related Epstein-Barr virus-associated B-cell lymphoproliferative disorders: special references to lymphomas surrounding this newly recognized clinicopathologic disease. Cancer Sci. 2008; 99 : 1085-1091.

13 Dojcinov SD, Venkataraman G, Pittaluga S, et al. Age-related EBV-associated lymphoproliferative disorders in the Western population: a spectrum of reactive lymphoid hyperplasia and lymphoma. Blood. 2011; 117 : 4726-4735.

14 Au WY, Loong F, Wan TSK, Tong ACK. Multi-focal EBVmucocutaneous ulcer heralding late-onset T-cell immunodeficiency in a woman with lupus erythematosus. Int J Hematol. 2011; 94 : 501-502.

15 Kleinman S, Jhaveri D, Caimi P, et al. A rare presentation of $\mathrm{EBV}+$ mucocutaneous ulcer that led to a diagnosis of hypogammaglobulinemia. J Allergy Clin Immunol Pract. 2014; 2 : 810-812.

16 Hart M, Thakral B, Yohe S, et al. EBV-positive mucocutaneous ulcer in organ transplant recipients: a localized indolent posttransplant lymphoproliferative disorder. Am J Surg Pathol. 2014; 38 : 1522-1529.

17 Gali V, Bleeker JS, Lynch D. Epstein-Barr virus positive mucocutaneous ulcer: a case report. S D Med. 2018; 71 : 252-255.

18 Satou A, Kohno A, Fukuyama R, Elsayed AA, Nakamura S. Epstein-Barr virus-positive mucocutaneous ulcer arising in a post-hematopoietic cell transplant patient followed by polymorphic posttransplant lymphoproliferative disorder and cytomegalovirus colitis. Hum Pathol. 2017; 59 : 147-151.

19 Nelson AA, Harrington AM, Kroft S, et al. Presentation and management of post-allogeneic transplantation EBV-positive mucocutaneous ulcer. Bone Marrow Transplant. 2016; 51 : 
300-302.

20 Bunn B, van Heerden W. EBV-positive mucocutaneous ulcer of the oral cavity associated with HIV/AIDS. Oral Surg Oral Med Oral Pathol Oral Radiol. 2015; 120 : 725-732.

21 Juan A, Lobatón T, Tapia G, et al. Epstein-Barr virus-positive mucocutaneous ulcer in Crohn's disease. A condition to consider in immunosuppressed IBD patients. Dig Liver Dis. 2017; $49: 934-937$.

22 Moran NR, Webster B, Lee KM, et al. Epstein Barr virus-positive mucocutaneous ulcer of the colon associated Hodgkin lymphoma in Crohn's disease. World J Gastroenterol. 2015; 21 : 6072-6076.

23 Di Napoli A, Giubettini M, Duranti E, et al. Iatrogenic EBVpositive lymphoproliferative disorder with features of EBV+ mucocutaneous ulcer: evidence for concomitant TCR $\gamma / \mathrm{IGH}$ rearrangements in the Hodgkin-like neoplastic cells. Virchows Arch. 2011; $458:$ 631-636.

24 Ohata Y, Tatsuzawa A, Ohyama Y, et al. A distinctive subgroup of oral EBV+ B-cell neoplasm with polymorphous features is potentially identical to EBV+ mucocutaneous ulcer. Hum Pathol. 2017; 69 : 129-139.

25 Yamakawa N, Fujimoto M, Kawabata D, et al. A clinical, pathological, and genetic characterization of methotrexate-associated lymphoproliferative disorders. J Rheumatol. 2014; 41 : 293-299.

26 Hashizume H, Uchiyama I, Kawamura T, et al. Epstein-Barr virus-positive mucocutaneous ulcers as a manifestation of methotrexate-associated B-cell lymphoproliferative disorders. Acta Derm Venereol. 2012; $92:$ 276-277.

27 Sadasivam N, Johnson RJ, Owen RG. Resolution of methotrexate-induced Epstein-Barr virus-associated mucocutaneous ulcer. Br J Haematol. 2014; 165 : 584.

28 Attard AA, Praveen P, Dunn PJS, James GJ. Epstein-Barr viruspositive mucocutaneous ulcer of the oral cavity: the importance of having a detailed clinical history to reach a correct diagnosis. Oral Surg Oral Med Oral Pathol Oral Radiol. 2012; 114 : e37-e39.

29 Matnani R, Peker D. Azathioprine induced Epstein Barr viruspositive mucocutaneous ulcer arising in perianal fistula and abscess associated with Crohn's disease. J Crohns Colitis. 2014; $8: 1747-1748$.

30 McGinness JL, Spicknall KE, Mutasim DF. Azathioprineinduced EBV-positive mucocutaneous ulcer. J Cutan Pathol. 2012; $39: 377-381$

31 Kanemitsu M, John D, Lim A, Jaffe ES, Aoki J. Clonal EpsteinBarr virus-positive mucocutaneous ulcer mimicking a mature B-cell lymphoma in a patient with mycophenolate-induced immune suppression. Leuk Lymphoma. 2015; 56 : 1908-1910.

32 Sadiku S, Kurshumliu F, Krasniqi X, et al. Age-related EpsteinBarr virus-positive cutaneous ulcer arising after a self-limited subcutaneous abscess: a case report. J Med Case Reports. 2012; $6: 288$.

33 Magalhaes M, Ghorab Z, Morneault J, Akinfolarin J, Bradley G. Age-related Epstein-Barr virus-positive mucocutaneous ulcer: a case report. Clin Case Rep. 2015; 3 : 531-534.

34 Soni S, Mercer R, Pattani K, Magill J. Epstein-Barr virus positive mucocutaneous ulcer: a rare lesion presenting as a large lower lip mass. Poster presentation from the University of Central Florida College of Medicine. 2014.

35 Hujoel IA, Rubio-Tapia A, Dao LN, Porrata LF, Kane SV. Epstein-Barr virus-positive mucocutaneous ulcer in an immunosuppressed patient. ACG Case Rep J. 2018; 5 : e32.

36 McCormack C, Huang Q. EBV + mucocutaneous ulcer: a new entity of WHO 2017. Blood. 2018; 131 : 1993.

37 Ravi PY, Sigamani E, Jeelani Y, Manipadam MT. Methotrexateassociated Epstein-Barr virus mucocutaneous ulcer: A case report and review of literature. Indian J Pathol Microbiol. 2018; $61: 255-257$

38 Daroontum T, Kohno K, Eladl AE, et al. Comparison of Epstein-Barr virus-positive mucocutaneous ulcer associated with treated lymphoma or methotrexate in Japan. Histopathology. 2018; 72 : 1115-1127.

39 Osman M, Al Salihi M, Abu Sitta E, Al Hadidi S. A rare case of Epstein-Barr virus mucocutaneous ulcer of the colon. BMJ Case Rep. 2017; 2017 : bcr-2017-220717.

40 Maffione AM, Rampin L, Paolini R, et al. Epstein-Barr viruspositive mucocutaneous ulcer mimicking rectal carcinoma at 18F-FDG PET/CT. Clin Nucl Med. 2017; 42 : 645-646.

41 Aldridge T, Paraneetharan, Brennan PA, Ilankovan V. EpsteinBarr-virus-related mucocutaneous ulceration that mimics oral squamous cell carcinoma: the importance of recognising this new condition. Br J Oral Maxillofac Surg. 2017; 55 : 418-419.

42 Chen BJ, Fang CL, Chuang SS. Epstein-Barr virus-positive mucocutaneous ulcer. Kaohsiung J Med Sci. 2017; 33 : 50-51.

43 Vatsayan A, Gupta A, Ahuja S, et al. Epstein-Barr virus-associated mucocutaneous ulcer in a patient with T-cell acute lymphoblastic leukemia: importance of accurate diagnosis and conservative management. J Pediatr Hematol Oncol. 2017; 39 : e338-e341.

44 Au JK, Said JW, Sepahdari AR, St. John MA. Head and neck Epstein-Barr virus mucocutaneous ulcer: Case report and literature review. Laryngoscope. 2016; $126: 2500-2504$.

45 Nakauyaca A, Kalro A, Donaldson E, Patel H. Fatal outcome of an Epstein-Barr virus positive mucocutaneous ulcer secondary to methotrexate. Intern Med J. 2016; $46: 1226-1228$.

46 Sinit RB, Horan KL, Dorer RK, Aboulafia DM. Epstein-Barr virus-positive mucocutaneous ulcer: Case report and review of the first 100 published cases. Clin Lymphoma Myeloma Leuk. 2019; 19 : e81-e92.

47 Pina-Oviedo S, Miranda RN, Medeiros LJ. Cancer therapyassociated lymphoproliferative disorders: an under-recognized type of immunodeficiency-associated lymphoproliferative disorder. Am J Surg Pathol. 2018; 42 : 116-129.

48 Teixeira Mendes LS, McCaul J, Wotherspoon A, Attygalle AD. Epstein-Barr virus-positive mucocutaneous ulcer with a background of Crohn's disease and Waldenström macroglobulinaemia: a case report highlighting diagnostic pitfalls. Histopathology. 2018; $72: 874-877$.

49 Swerdlow SH, Quintanilla-Martinez L, Willemze R, Kinney MC. Cutaneous B-cell lymphoproliferative disorders: report of the 2011 Society for Hematopathology/European Association for Haematopathology workshop. Am J Clin Pathol. 2013; 139 : 515-535.

50 EPSTEIN-BARR VIRUS. International Agency for Research on 
Cancer Monographs on the Identification of Carcinogenic Hazards to Humans. 2012; 100B : 49-92.

51 Deeming GMJ, Collingwood J, Pemberton MN. Methotrexate and oral ulceration. Br Dent J. 2005; $198: 83-85$.

52 Gion Y, Iwaki N, Takata K, et al. Clinicopathological analysis of methotrexate-associated lymphoproliferative disorders: Comparison of diffuse large B-cell lymphoma and classical Hodgkin lymphoma types. Cancer Sci. 2017; 108 : 1271-1280.
53 Ghia P, Prato G, Stella S, et al. Age-dependent accumulation of monoclonal CD4 + CD8 + double positive T lymphocytes in the peripheral blood of the elderly. Br J Haematol. 2007; 139 : 780-790. 